\title{
HACIA UNA SEMIÓTICA TEXTUAL PEIRCIANA (I)
}

\author{
Dinda L. Gorlée
}

SIGV, La Haya \& Universidad de Viena

\section{(1) UNA DEFINICIÓN FUNCIONAL DE TEXTO}

El objeto de este proyecto de investigación es el fenómeno texto. Parecerá obvio empezar con una definición de lo que exactamente debe entenderse por el término texto, pero no resulta sencillo. El término texto no solamente se utiliza para referirse a objetos muy dispares, sino que además puede contemplarse desde numerosos puntos de vista. En la actualidad, casi cualquier secuencia de palabras - Guerra y paz, un haiku, la letra de una canción de los Beatles, el Diario de Ana Frank, una lista de la compra, una entrevista radiofónica, una receta médica, etc.- puede considerarse texto y, por lo tanto, ser filtrado a través de la misma malla de procesado textual. Lo mismo puede aplicarse a fenómenos no verbales o parcialmente verbales como un tebeo, la representación de una ópera, un paisaje urbano o una vestimenta teatral. Lo que diferentes textos tienen en común y lo que los diferencia 
ha quedado, demasiado frecuentemente, implícito y, al parecer, ha de ser comprendido intuitivamente. Consiguientemente, lo que es un texto (y lo que no es un texto) es sujeto de interpretaciones muy diversas y, más que aclarado, se ha oscurecido. A pesar de esta confusión, el término texto se utiliza y se comprende constantemente, por lo que debe suponerse que, llegado el caso, intuimos de alguna manera si el objeto que tenemos delante puede o no calificarse de texto, comprensión que manifiestamente no necesita una definición formulatoria para producirse.

Aun concebido como entidad exclusivamente verbal, el fenómeno texto no puede ser estudiado únicamente con métodos lingüísticos. El estudio textual ha pertenecido tradicionalmente al dominio de la erudición literaria, junto con otras disciplinas orientadas al texto verbal como la etnología/etnografía, la historia, la filosofía, los estudios religiosos y los estudios jurídicos. A ellas se han unido más recientemente la sociología, la psicología y la psiquiatría. La investigación teórica del texto es en alto grado interdisciplinaria (o transdisciplinaria). Esta investigación, además de las disciplinas relacionadas con el lenguaje -como poética, retórica, estilística, lingüística (general), semántica, (pragma) lingüística, teoría del acto lingüístico, teoría del signocomprende otras disciplinas humanísticas como la filosofía en sus varias ramas y especialidades, la psicología, la sociología, la etnometodología, así como otros campos de investigación interdisciplinaria - teoría de la traducción ${ }^{1}$, el estudio de la inteligencia artificial, teoría de la información, etc- Podemos pues concluir de este complejo transdisciplinario que la mejor manera de analizar el fenómeno texto es mediante una aproximación holística, en el marco de la semiótica general.

La dificultad de llegar a una definición concisa y a la vez exhaustiva de texto también se refleja en el escaso acuerdo que existe entre los teóricos sobre lo que exactamente constituye un texto. Para citar un ejemplo: Sture Allén observa que un texto escrito o hablado puede entenderse, entre otras cosas, como:

...un mensaje en una situación comunicativa, una acción, la manera de organizar un contenido dado, el modelo de un mundo posible, un medio de suprimir información, un campo experimental de análisis gramatical y léxico, la

1 Sobre este campo de investigación, véase Gorlée (1992) y las referencias que allí se facilitan. 
aplicación de un modelo generativo, un flujo de datos lingüísticos, el reflejo del temperamento de un autor, un cuadro de costumbres, un pronóstico de ciertas reacciones en el receptor o receptores (Allén, 1982: 15-16) ${ }^{2}$.

Lo que estas descripciones dispares tienen en común es que todas pueden referirse a un objeto significativo, observable, pero nada más. De esta lista, de ningún modo exhaustiva, se desprende que texto, como noción y como artefacto puede interpretarse de muchas maneras diferentes y que aunque se conciba exclusivamente como entidad lingüística, no es posible estudiarlo adecuadamente exclusivamente con métodos lingüísticos. Como se ha indicado, dado el carácter transdisciplinar de las investigaciones textuales, el fenómeno del texto debe investigarse holísticamente en el marco de la semiótica de tradición norteamericana. Brevemente, lo que me propongo es razonar esta decisión metodológica y desarrollar una teoría (aún provisoria y parcial) del texto basada en las ideas semióticas de Charles Sanders Peirce.

Si bien el concepto de texto resulta difícil de definir, ello no ha impedido que se haya intentado repetidamente. Ciertamente, texto ha sido definido y redefinido una y otra vez por multitud de estudiosos y desde muy diferentes puntos de vista. Lo que hay que integrar en tal definición son los dos aspectos, al menos, de «lo que es un texto». Por una parte, debe clarificarse el status ontológico adjudicado a la entidad «texto» (abstracto/concreto, general/individual, código, productor, receptor) y, por otra, deben establecerse las cualidades «esenciales» de los textos (Lieb, 1981). Con un enfoque lingüístico, repetimos, estos problemas sólo pueden tratarse parcialmente; mientras que desde la más amplia perspectiva de la semiótica general debe considerarse que un texto es un signo linguiístico complejo, expresado en lenguaje articulado y que funciona como agente comunicativo. En sus definiciones (y repetidas redefiniciones) Peirce no identifica signo con signo lingüístico, sino que considera signo cualquier fenómeno perceptible (visual, auditivo, olfativo u otro) que funciona como signo; es decir, que comunica un mensaje a alguna mente que lo interpreta. En esta amplia concepción del signo, el intercambio de mensajes en el lenguaje verbal (es decir, en textos) es una forma de comunicación, restringida a los humanos y altamente sofisticada si se la compara con los actos de comunicación no verbales que tienen lugar entre todos los seres vivientes, tanto humanos como no humanos. Con todo lo vago,

2 Todas las traducciones son mías. 
y quizás demasiado amplio que pueda parecer a primera vista el concepto peirciano de signo, me aventuro a sugerir que puede utilizarse con fruto en toda su amplitud si se aplica, primero a la definición y, luego, a la subsiguiente investigación del fenómeno, verdaderamente calidoscópico, del texto.

Antes de pasar a centrarme en el concepto semiótico de texto, presentaré varias definiciones procedentes de diferentes teorías linguiísticas o relacionadas con la linguística. Dado el objetivo de este artículo, debo limitarme a una selección de las definiciones, sin pretender tampoco discutirlas exhaustivamente. Lo que frecuentemente constituye un problema a la hora de distinguir entre un concepto lingüístico y un concepto semiótico del texto es que las teorías semióticas basadas en Ferdinand de Saussure, a diferencia de las basadas en Peirce, son fundamentalmente linguísticas y toman el lenguaje como modelo director. Así lo ilustra Klaus Brinker en su definición de texto como «una secuencia coherente de signos verbales o complejos de signos que no se hallan incrustados en otra unidad más extensa» (Brinker, 1979: 3). En esta más bien estática definición, se acentúa la sintaxis (estructuras de signos y su relación jerárquica), mientras que el significado y el uso (los aspectos semánticos y pragmáticos) se difuminan y hasta se ignoran.

Los lingüistas británicos Michael Halliday y Ruqaiya Hasan (1976: 1) definen el texto así: «La palabra TEXTO se utiliza en lingüística para referirse a un pasaje, escrito o hablado, de cualquier extensión, que forma un conjunto unificado». Más tarde esta definición, que abarcaría todas las expresiones verbales se matiza y modula:

\begin{abstract}
Generalmente, sabemos cuando un espécimen de nuestro lenguaje constituye un texto o no. Esto no quiere decir que nunca puede haber certeza. La diferencia entre un texto y una colección de oraciones sin relación entre sí es después de todo una cuestión de grado... Un texto puede ser hablado o escrito, prosa o verso, diálogo o monólogo. Puede ser cualquier cosa, desde un simple proverbio a toda una obra dramática, desde un breve grito de socorro a un debate de horas en una reunión. Un texto es una unidad de lenguaje en uso. No es una unidad gramatical, como una cláusula u oración ... Un texto no es algo como una oración, sólo que más grande; es algo con carácter diferente al de una oración. Un texto debe considerarse una unidad SEMÁNTICA: una unidad, no de forma, sino de significado (Halliday y Hasan, 1976: 1-2).
\end{abstract}

Esto significa que, más allá de la intuición, existe una distinción linguiística (al menos en principio) entre lo que es texto y lo que no lo es, 
y que esta distinción tiene como base el significado. Un texto tiene sentido, mientras que un no-texto no lo tiene; la diferencia está en la presencia o ausencia de lo que se llama textura. Para Halliday y Hasan (1976), textura es lo que define a un texto, en oposición al objeto verbal sin textura, el no-texto. Textura es la propiedad de conexión, resultado del establecimiento de relaciones lexicogramáticas que enlazan entre sí las partes del texto; y el texto deriva su textura del hecho de que funciona como una unidad significativa con respecto a su situación contextual, es decir, a su entorno sociocultural.

Este concepto funcional-semántico del texto de Halliday y Hasan ha sido más tarde adoptado y desarrollado en la lingüística textual. Según Harald Weinrich:

\footnotetext{
Entre todas las unidades lingüísticas imaginables, la unidad oral o escrita llamada «texto» (más precisamente, «texto-en-una-situación») es la que ocupa el lugar más prominente como única unidad dada. Confinada por unos marcadores que delimiten su uso comunicativo ... se entiende como evidencia comunicativa. El texto no necesita ser definido (1981: 228).
}

Si se da por descontado que el texto es el «primum datum de la lingüística» (Weinrich, 1981:228), está asimismo claro que este lingüista considera el texto como una unidad de comunicación. Así lo vuelven a afirmar más explícitamente Robert De Beaugrande y Wolfgang Dressler (1981: 3-14 y passim), para quienes un texto es un suceso, un «sucedido comunicativo» en el cual deben cristalizarse siete cualidades de lo que ellos llaman textualidad. Estas cualidades son cohesión, coherencia, intencionalidad, aceptabilidad, informatividad, situacionalidad e intertextualidad (vid. De Beaugrande y Dressler, 1981).

La siguiente definición en la que se acentúa la dimensión comunicativa del texto es de Pier M. Bertinetto: «A manera de esbozo y provisionalmente, esta unidad podríamos entenderla como una expresión verbal tal que: (a) es producida por un emisor real (esto es, por un individuo único definido en el tiempo y el espacio), y (b) constituye un acto comunicativo completo» (1979: 144). En esta visión pragmática, la cualidad de «ser un texto»-su textura, su textualidad - se define situando el texto, no en un marco meramente lingüístico, sino en el marco de la teoría del acto comunicativo: «[U]n T[exto] es un conjunto de oraciones (o posiblemente una sola oración) que es (a) temáticamente coherente, (b) tiene una función comunicativa que depende de un potencial elocutivo claramente 
definido y (c) se produce dentro de una performancia comunicativa concreta (en términos de tiempo y espacio)» (Bertinetto, 1979: 145146). Un enfoque comunicativo como el de Bertinetto, que trata el texto como manifestación del uso linguiístico, va más allá de la lingüística textual y se acerca a una perspectiva semiótica aunque sin aprovechar conceptos de la teoría de los signos.

Teun Van Dijk se centra en «el "componente" "comunicativo" o pragmático» del texto, intentando «extender más aún la gramática y la competencia» (1972: 3). En este punto, la teoría de Van Dijk concuerda con la ya citada propuesta de definición de Bertinetto, con la que también coincide al concentrarse principalmente en «un tipo particular de texto: la literatura» (Van Dijk, 1972: 1), reduciendo así el campo de aplicación de la teoría del texto a las formas estéticas, no utilitarias del uso del lenguaje. Van Dijk define el texto, contraponiéndolo a discurso (o expresión verbal), como «la noción abstracta de TEXTO, subyaciente a lo que intuitivamente se conoce por 'discurso conexo' (Van Dijk, 1972: 1) $)^{3}$.

En la posterior teoría del texto, esta distinción entre el discurso concreto ( $\mathrm{o}$, al menos, observable) y el texto teórico abstracto, ha sido transcendida mediante una definición en la que se reconoce que texto (o discurso) es una noción operacional/funcional y que «ser un texto» no puede ser considerado una propiedad inherente a ciertos objetos lingüísticos; es más bien que un objeto lingüístico se convierte en texto porque una persona (del lado emisor o del lado receptor del mensaje verbal) decide, por razones extralingüísticas, considerarlo como texto. En palabras de János Petöfi:

3 Como resultado de la extensión del campo de aplicación del término texto, en la actualidad discurso y texto se utilizan casi indistintamente (ver Petöfi, 1986b: 1080). Originariamente, discurso se reservaba para referirse únicamente a expresiones orales; pero si bien De Saussure se concentró sobre todo en los signos linguísticos acústicos (utilizaba texto sólo en el sentido filológico, referido a los textos clásicos), en Europa el estudio de la lengua hablada o análisis del discurso, recibió relativamente poca atención hasta la llegada de la teoría del acto linguíístico. Para una discusión detallada del uso de texto y discurso en lingüística textual y la teoría del texto, veánse los informativos estudios de Vitacolonna (1988) y Virtanen (1990). En sus trabajos más recientes, Van Dijk parece haberse alejado de su linguística textual aplicada al texto literario y pasado a la psicología cognitiva (y social) y la inteligencia artificial. Este nuevo interés de Van Dijk por la comprensión cognitiva del discurso le ha conducido al estudio de macroestructuras semánticas (estructuras de nivel superior de presentación y procesamiento de información). Por ello, la antigua dicotomía texto-discurso de Van Dijk ha quedado un tanto desdibujada y parece haber sido desplazada por la noción (unificada) del uso de la lengua, el cual «se manifiesta en expresiones que, como objetos-tipo, interpretamos como discursos o textos de determinada lengua natural» (Van Dijk, 1980: 5). 
Para un productor o receptor de un objeto verbal hablado o escrito, un texto es un objeto que, a su juicio, en una determinada situación comunicativa puede/debe ser tratado como una totalidad completa y conexa. Esta opinión se basa en factores extra-textuales que a la hora de la recepción tienen un impacto decisivo en el análisis/interpretación de los factores intra-lingüísti$\cos$ (1986a: 545).

Petöfi define un texto como «un objeto ordenado linealmente con un constituyente básico que consiste únicamente de signos verbales, $o$ que tiene un núcleo predominantemente verbal, y que además satisface el criterio de definición del analizante» (1986b: 1081). Si el «analizante» puede más o menos libremente decidir qué propiedades hay que considerar «esenciales» en un objeto verbal tal como existe en la realidad, para poderlo calificar de texto, habría que concluir que «ser un texto» está exclusivamente determinado por el propósito del análisis.

El principal objetivo del presente estudio es semiótico. Por ello, en lugar de continuar con más definiciones inspiradas en la lingüística, trataré de señalar cómo la concepción semiótica del signo se aplica a la definición y operacionalización de mensajes verbales escritos de todo tipo ${ }^{4}$. No podrá tratarse aquí, por lo tanto, la cuestión de si los textos escritos son representaciones del lenguaje hablado; como, en general, tampoco la de la relación entre el discurso escrito y el hablado. Por otra parte, una verdadera teoría semiótica del texto debe abarcar los textos de todo tipo, y no concentrarse en uno de ellos (en textos literarios, por poner un ejemplo) con exclusión de los demás. El propósito

4 Si nos reducidos a los textos escritos, la noción de documento deja fácilmente aceptarse como un posible equivalente. A pesar de las correspondencias que existen a primera vista entre ambos términos, su uso se bifurca rápidamente. Originalmente el término documento significaba una hoja de papel (testamento, pasaporte, partida de matrimonio, escritura, etc.) con un efecto reconocido oficialmente y una función bien definida dentro del sistema legal - como también, tratándose de un documento histórico, significaba material (en este caso) escrito que como relación de una realidad pasada permite al historiador historiografiar (es decir: escribir la historia). En estos últimos electrónicos años ha sido adoptado por los fabricantes de procesadores de textos para referirse especialmente a la clase de archivos que pueden verse en el menú de entrada. Se ha convertido por tanto en un término abanico que cubre cualquier cosa desde un archivo "sólo-texto» de procesador de textos hasta una hoja electrónica o una página interactiva de la Web. Lo que es más, con la llegada de los multimedia, los documentos-textos abarcan ahora elementos tales como imagen, sonido, movimiento, y hasta de tacto (el ratón y el touch-pad en ordenadores, la pantalla que reacciona al tacto en las copiadoras y máquinas automáticas de café, etc.). Sólo falta que en un futuro próximo se añadan los elementos olfativos para que en las pantallas se exploten todos los sentidos interactivamente, con lo que el paisaje textual disponible para la comunicación humana se hará aún más completo y complejo, y el desarrollo progresivo desde lo concreto hacia lo abstracto de los medios se empujará hasta sus límites. 
del presente estudio es estudiar los signos textuales, su papel en la comunicación humana y lo que significan.

En el prefacio a su original Semiotic Foundations: Steps Toward an Epistemology of Written Texts, Floyd Merrell hace la siguiente afirmación:

\begin{abstract}
Que yo sepa, no existe una definición adecuada de «texto». Lo que he hecho en lugar de emprender la ardua tarea de definir el término, para disgusto quizás de los puristas que incesantemente buscan concisas definiciones antes de seguir adelante, ha sido simplemente establecer los parámetros que delimitan el tipo específico de texto a tratar. «Textos escritos», tal como se usará más adelante, implica todo el corpus escrito en lenguas naturales y/o artificiales con el propósito de comunicar observaciones, ideas, pensamientos, intuiciones, sentimientos y emociones. Está claro que de esta clasificación quedan excluidos tanto el discurso verbal de la tradición oral - caso de los mitos y cuentos tradicionales- como los textos fílmicos y otros textos icónicos. No obstante, la clase general de textos escritos incluye definitivamente un amplio espectro que desde la poesía y a través de obras religiosas, filosóficas e históricas, llega al periodismo, y luego a los informes de ciencias naturales y sociales y hasta las pruebas matemáticas (1982: vii).
\end{abstract}

Aunque esta formulación no deja de ser modesta y Merrell parece incluso querer disculparse, su «observación introductoria» muestra de hecho una definición de excelente sentido común, una definición funcional de texto escrito (en contraposición a una definición analítica) que se distingue por su claridad no doctrinaria entre la maraña de otros intentos. Ésta es la definición de la que me serviré en este artículo. Sin embargo, el término corpus de la definición descriptiva de Merrell debe especificarse aún más y, para el propósito de este estudio, semiotizarse. Desde una visión semiótica, un texto es cualquier cosa o objeto verbal escrito que es, en primer lugar, reconocible materialmente y delimitable como tal, que es, en segundo lugar, deícticamente anclado en el tiempo y espacio real o «real», y que, en tercer lugar, adquiere significado al ser usado en un contexto social. Esto no excluye de ninguna manera la creación de un significado privado, al menos en el marco semiótico de Peirce, en el que la significación social incluye y presupone el significación privada. Siguiendo a Larsen (1994: 3826) podemos añadir a tal definición que un texto es un «complejo de signos realmente efectuados, filtrados a través de la lógica discursiva de la intencionalidad». Si bien el orden secuencial irreversible en que se presenta un texto verbal es una condición previa para que se produzca una significación intersubjetiva, esta producción del significado, empero, tiene lugar en dos planos tanto sucesivos como simultáneos: 
un plano serial y un plano estructural. Que la lectura del texto pueda ser lineal, a saltos hacia adelante y atrás, o reversible, cobra dimensiones dramáticas en la lectura rapsódica del texto electrónico.

\title{
(2) PALABRA, ORACIÓN Y TEXTO
}

Como ya se ha dicho, el estudio de los textos ha sido tradicionalmente el dominio de los estudios literarios, en compañía de otras disciplinas orientadas al texto como la etnología/etnografía y los estudios religiosos/teológicos, históricos, filosóficos y jurídicos. A ellos se han unido más recientemente la sociología, la psicología y el psicoanálisis/la psiquiatría. Si la lingüística tradicional se ha ocupado primariamente del lenguaje como totalidad, en la práctica se ha concentrado en el estudio de pequeñas unidades del lenguaje, a nivel de palabra y/o oración. El resultado de este estudio se presentaba como aplicable al lenguaje en su totalidad. Según $Z$. Harris en su (originalmente de 1952) Análisis del discurso:

\begin{abstract}
La lingüística descriptiva generalmente no sobrepasa el límite de la oración. Esto no se debe a una decisión previa. Las técnicas de la lingüística se elaboraron para estudiar un trecho de texto de cualquier longitud. Pero resulta que en todos los lenguajes los logros se limitan a un trecho relativamente corto... Esta limitación no parece demasiado seria, porque no ha impedido que se escribieran gramáticas adecuadas: la gramática establece la estructura de la oración; el hablante produce una oración en consonancia con esta estructura, proporcionando una determinada secuencia de oraciones (citado en Saporta y Sebeok [1959]1972: 43-44).
\end{abstract}

El concepto tradicional de la palabra como unidad básica teórica (al menos, empírica) del comportamiento verbal y por lo tanto de la descripción lingüística, ya fue atacado por Saussure, para quien «la unidad concreta no debe buscarse en la palabra, sino en otra parte ... Una teoría bastante extendida hace de la oración la unidad concreta de lenguaje; hablamos sólo con oraciones, y después distinguimos las palabras» ([1916]1949: 105-106). Siguiendo esta misma dirección, en su Syntactic Structures de 1957, Noam Chomsky afirma: «De aquí en adelante, consideraré que un lenguaje es un conjunto (finito o infinito) de oraciones, de longitud finita y construidas con un número finito de elementos» (1957: 13). En 1968, más de diez años después de Syntactic 
Structures, la «gramática de casos» de Charles Fillmore continúa limitándose a la oración: «La oración, en su estructura básica, consiste en un verbo y una o más frases nominales, cada una de ellas asociadas con el verbo mediante una determinada relación "casual"» (Fillmore, 1968: 21). Dicho en términos semiológicos más abstractos, cada «caso» representa una posición actancial con su correspondiente función narrativa (Greimas y Courtès, 1979: 3 y passim). En su «gramática universal» de 1972, tampoco Richard Montague va más allá del nivel oracional cuando afirma:

La tarea de la sintaxis de una lengua es denominar sus objetos lingüísticos (palabras, oraciones y sus partes en la medida en que éstas tengan función sintáctica) y de explicitar sus propiedades sintácticas y relaciones internas (Montague y.Schnelle, 1972: 5).

En oposición a esta supremacía de la oración, el estructuralismo clásico europeo, con Roman Jakobson como su más eminente representante, eligió tempranamente como objeto de estudio, no ya la oración o la palabra, sino el texto o el discurso ${ }^{5}$. Ocurre lo mismo en otra rama del estructuralismo linguíístico, la «glosemática» de Louis Hjelmslev. Para Hjelmslev en su Omkring sprogteoriens grundlaggelse de 1943 (traducido al castellano como Prolegómenos a una teoría del lenguaje) el lenguaje es un conjunto de textos, y:

\begin{abstract}
Si algo le es dado al investigador linguiístico... es el texto no analizado en su integridad indivisa y absoluta. El único procedimiento a seguir si deseamos construir un sistema para procesar tal texto, será un análisis en el cual el texto es considerado como una clase analizable en unos componentes que, a su vez, son susceptibles de análisis, y así seguido hasta que el análisis sea exhaustivo... El objeto de interés de la teoría lingüística son textos. El propósito de una teoría lingüística es proveer un método de procedimiento mediante el cual un texto dado puede ser comprendido a través de una descripción auto-consistente y exhaustiva ([1943] 1961: 16).
\end{abstract}

$\mathrm{El}$ «método de procedimiento» mencionado por Hjelmslev era concebido por él como un modelo de pensamiento de carácter bilateral y combinatorio. Siguiendo a Saussure, Hjelsmlev distinguía en el signo lingüístico dos planos, a los que él denominaba «plano de expresión» $\mathrm{y}$ «plano de contenido». Ambos planos pueden ser a su vez subdividi-

5 Véase Van Dijk (1972: 25 y ss.) y Rieser (1981). 
dos en unidades más pequeñas, tales como «fonemas» en el plano expresivo y «semas» en el de contenido. Hjelmslev partía por lo tanto del texto como totalidad, procediendo deductivamente «hacia abajo» desde el nivel textual. Otros lingüistas después de él, sin embargo, invirtieron esta forma de proceder para llegar inductivamente al nivel del texto. Éste es claramente el caso de los norteamericanos Zellig Harris y Kenneth L. Pike, quienes, aunque con teorías y puntos de vista divergentes, se concentran en las unidades lingüísticas que van más allá de la oración, oponiéndose así a Chomsky. Antes de que Chomsky publicara su Syntactic Structures, ya el «análisis del discurso» de Harris de 1952 se apoyaba en el nivel textual tomando el «discurso... como la más completa unidad de ámbito para la investigación distribucional» (1954: 158). El «análisis del discurso» de Harris (1952, reimpreso en 1963) es «un método de búsqueda en cualquier material discreto y conexo, sea lingüístico o casi-lingüístico, compuesto por más de una oración elemental, alguna estructura global que caracteriza la totalidad del discurso (el material lineal ) o extensas partes del mismo» (Harris, 163: 7). Harris proponía un análisis «distribucional» de las equivalencias estructurales en y entre oraciones sucesivas. Su lingüística descriptiva transfrástica y transoracional, se ocupa de la ocurrencia y distribución de repeticiones y paralelismos en el nivel sintáctico, así como de sus combinaciones. Harris, al igual que Chomsky, rechazaba que el significado fuese relevante fuera de la identificación de la repetición como rasgo significativo. Para engrosar el número de equivalencias, Harris proponía la «transformación» gramatical de las secuencias verbales estudiadas por él. El concepto de «transformación», introducido por Harris, fue luego elaborado por su discípulo Chomsky, quien también seguía a Harris al concentrarse exclusivamente en las relaciones morfosintácticas - la famosa «gramaticalidad» de las secuencias verbales lógicas, o «bien formadas»sin prestar atención a las relaciones de tipo semántico. La aparente ceguera de Chomsky ante la semántica repercutiría fuertemente no sólo en la lingüística chomskiana «pura» sino también en el análisis lingüístico aplicado (esto es, el análisis lingüístico que utiliza métodos linguiísticos o —en el caso del estructuralismo- métodos «lingüísticos»).

En el análisis lingüístico creado por Pike, el significado es un componente esencial. En su monumental obra Language in Relation to a Unified Theory of the Structures of Human Behavior ([1954] 1967), Pike acuñó el término tagmema para referirse a la secuencia verbal, de ahí que su teoría se llame tagmémica. Compuestos de gramática y forma por un lado, y de significado (tanto significado léxico como 
significado estructural, o distribucional) por otro, tagmemas son estructuras discursivas en las que ambos aspectos funcionan interdependientemente. Pike analizó estos tagmemas siguiendo el método llamado slot-and-filler, que él mismo creó. Su método distingue entre segmentos tagmémicos que, por un lado, son slots funcionales dentro de la pirámide jerárquica de la gramática del texto, que va desde el nivel de morfema a la palabra, la frase, la cláusula, la oración, el párrafo hasta el discurso o texto entero; y por otro, los tagmemas realizan tal función porque tienen una forma o clase gramatical particular, capaces de llenar el slot, de ahí el término de filler. De este modo Pike construyó matrices descriptivas de lo que él llamó «hiper-enunciados», agrupaciones verbales (escritos y/o habladas) en torno a uno o más tagmemas como núcleo. Según Pike, «la oración es pues totalmente inadecuada como punto de partida (y de llegada) [y] no pueden analizarse sin recurrir a relaciones de nivel superior» (1967: 147). Además, en vivo contraste con otras teorías, «puras» en el sentido de exclusivamente linguísticas, la doctrina de Pike integra elementos antropológicos en el análisis lingüístico. Esto le hace concebir los enunciados verbales en su relación con los hechos no verbales que rodean, acompañan y/o determinan la realización del acto verbal desde el contexto directo de la situación comunicativa hasta la cultura como totalidad. La doble estructuración jerarquizada del acto verbal no se limita en absoluto a la frase, cláusula o oración, sino que

... empieza necesariamente por el hecho verbal total considerado dentro de su entorno cultural total, el cual presupone a su vez un entorno físico total. Gracias a este engranaje de unos elementos en niveles o planos de integración cada vez más altos, estamos obligados a tratar la lengua como una sola fase del comportamiento humano, estructuralmente integrada en él (Pike, 1967: 484).

Esto lleva a Pike a sobrepasar el límite del hiper-enunciado y a «partir del comportema compuesto» (1967: 147), de cualquier extensión. Incluso introduce la noción y el término hiper-comportema (1967: 130) como unidad mayor y compleja del comportamiento humano, mixto de verbal y no verbal y ejemplificado por Pike en sus análisis de un servicio religioso, un partido de rugby y un desayuno familiar.

La amplitud del marco conceptual de Pike, junto con sus múltiples posibilidades de aplicación, distingue la tagmémica de los demás enfoques tanto anteriores como posteriores a él, y lo convierte en una figura clave del desarrollo interdisciplinar (o transdisciplinar) del análisis 
lingüístico de textos. No es extraño que la manera en que las clases referenciales (fillers) de Pike (tales como actor, propósito, recipiente de una acción, tiempo, lugar) «llenan» los «huecos» (slots) tagmémicos (tales como sujeto, objeto, predicado) se parezca a los «casos» de Fillmore y a los «actantes» de Greimas. El método slot-and-filler de Pike se inspira en el modelo hjelmsleviano con su dicotomía formasubstancia y su doble articulación en el nivel gramatical y el nivel referencial, apoyándose en última instancia, si bien implícitamente, en la saussuriana relación significante-significado. Si esta dicotomía ya indica claramente la presencia de un espíritu estructuralista, esta orientación parece confirmarse en las inquietudes etnolingüísticas de Pike; pues si por una parte el método de Pike parece hacerse eco de las funciones narrativas de Vladimir Propp, por otra se aproxima a las ideas de Claude Lévi-Strauss y Bronislaw Malinowski. A pesar de las diferencias que median entre la antropología funcional de éste y la antropología estructural de aquél ${ }^{6}$, ambos investigadores ponen énfasis en la íntima relación entre el comportamiento verbal y el no verbal, y ambos describen y analizan los signos simbólicos (verbales y no verbales) como entidades enraizadas en la cultura humana y condicionadas por ella.

Mediante su absorción de muy distintas ideas y perspectivas propuestas por otros tantos estudiosos, el estructuralismo francés ambicionaba ser, o al menos convertirse en la «teoría total» apuntada y defendida por Pike. Sin embargo, como ya he argumentado en otro lugar (Gorlée 1992), el estructuralismo debido a ciertas inherentes y autoimpuestas limitaciones, no puede naturalmente ser, o convertirse en una herramienta de método universal. Baste recordar en este punto que una razón de ello es que el método semiológico-estructural, o mejor, el método estructuralista resulte en principio menos adecuado para aplicarlo a hechos no lingüísticos que el llamado semiótico. Éste último, del que el método dinámico-procesal de Peirce es el ejemplo modelo, está mejor

6 En la introducción de su Man's Glassy Essence, Milton Singer observa que las divergencias entre Lévi-Strauss y Malinowski «pueden ser intrepretadas por el contraste Saussure-Peirce, es decir entre una relación diádica del signo, en la cual imágenes (significantes) reciben sus «sentidos» o «conceptos» (significados) a partir de un código lingüístico convencionalizado (langue), y una relación triádica del signo, en la cual el signo denota un objeto, significa una propiedad o una relación de este objeto, e interpreta a otro signo en un intercambio infinito entre emisores e intérpretes del signo» (1948:5). Semejante division d'esprits no sólo sufre la antropología sino que ha creado una controversia «ideológica» entre «semiólogos» y «semióticos» en cada uno de las disciplinas y los campos de investigación donde se aplica la teoría de los signos, así como en la teoría semiótica general. 
equipado para describir el flujo del lenguaje y en el lenguaje, que un sistema como el estructuralista que, con su carácter estático de oposiciones binarias, ha sido diseñado precisamente para detener flujos.

El enfoque de Pike ya preludia algunos aspectos de la lingüística de textos, la llamada gramática del texto y en particular la teoría Textstruktur-Weltstruktur de János Petöfi ${ }^{7}$. A partir de los años sesenta, a medida que surgían, las teorías sobre textos fueron adquiriendo diferentes nombres y etiquetas como «lingüística de textos», «procesamiento de textos», «textología», «gramática de textos», «gramática del discurso», «teoría del texto», «análisis del discurso», «pragmática de textos», «semántica de textos» y finalmente «semiótica del texto», que no por ser la última es por ello menos importante ${ }^{8}$. La similitud entre el enfoque de Pike y el estudio linguíistico/gramatical del texto es sin embargo más aparente que real. Esto se debe a que la linguiística y la gramática de textos buscaron sistemáticamente progresar siguiendo el camino de la formalización lógica. Así cumplían la exigencia de Chomsky, quien afirmaba que para ser científica una teoría lingüística debía ser formal, lo cual asimismo implica que tanto la lingüística como la gramática de textos rechazaban un supuesto básico de Pike, a saber, que «la tagmémica fue concebida como parte de la estructura del comportamiento, y no simplemente como sistema algebraico formal», mientras que «la necesidad de componentes intuitivos en la acción del analista excluye proceder según un algoritmo analítico» (Pike, [1954]1967: 501, 289). En efecto, Pike recalca que lo que él llama «pasos intuitivos» 0 «saltos analíticos» ([1954]1967: 224-225) son elementos cruciales de su análisis linguiístico y los procedimientos basados en el mismo. Según esta visión, la intuición permite al lingüista «identificar, toscamente, éticamente, con un amplio margen de error algo de las características en los datos antes de aplicar sus rigurosos procedimientos émicos a este material para llegar a un refinamiento estructural de aquel material». (Pike, [1954]1967: 224) ${ }^{9}$.

7 Véase mi Hacia una semiótica textual peirciana (II), la segunda parte de este artículo, que aparecerá en el próximo número de Signa.

8 Véase Petöfi (1986b: 1080 y ss.).

9 Ético y su opuesto, émico, son neologismos de Pike que se refieren a dos enfoques diferentes al análisis y la descripción del comportamiento humano tanto verbal y no verbal. El que lo estudia éticamente «mide por un mismo rasero todas las culturas o lenguas, o una parte de ellas», mientras que la visión émica es «al contrario, culturalmente específica y se aplica a una sola lengua o cultura a la vez» (Pike, 1967: 37). «El punto de vista ético observa el comportamiento desde fuera del sistema particular y como un primer acercamiento esencial para estudiar el sistema ajeno» mientras que «el punto de vista émico estudia el comportamiento como colocándose dentro del sistema» (Pike 1967:37). Las nociones ético-émico gozan de particular popularidad en los estudios antropológicos y etnológicos. Para más detalles, véase Brend (1986). 
Primeramente, se descubre el significado intuitivamente; sólo después pueden los datos ser aprovechados con métodos descriptivos formales. En contraposición a los transformacionalistas y sus sucesores en materia de linguística y gramática de textos, Pike afirma sin reservas que «no existe un procedimiento mecánico de descubrimiento» a través del cual puede obtenerse el significado (Pike, [1954]1967: 225 nota), y añade:

Rechazamos vehementemente la añadidura — no por implícita menos gratuita- del término «mecánico» a la frase «procedimiento de descubrimiento». En cambio, nos convencen los procedimientos de descubrimiento del tipo «adivina y comprueba»... Una vez que se haya formado un sistema mediante tales procedimientos, que contienen componentes intuitivos, se procede a la descripción que, a diferencia del descubrimiento, puede optar por procesar sólo la parte formal de los datos disponibles y omitir el componente semántico. Yo he optado por conservar los componentes semánticos por una razón sencilla: después de establecer la estructura de una secuencia linguística, me interesa poder saber lo que significa - no sólo que esté bien formada- - , pues el lenguaje es ante todo un sistema comunicativo (Pike, 1967: 225 nota).

En muchos aspectos, el razonamiento de Pike parece separarse del pensamiento estructuralista, al que hizo valiosas contribuciones, y parece acercarse al de Peirce. Lo que se subraya en la cita - la intuición como paso inicial en el proceso de descubrimiento, intuición de la cual debe arrancar el ímpetu hacia un razonamiento lógico- evoca claramente el concepto peirciano de abducción, o razonamiento instintivo, que si bien posee un carácter radicalmente conjetural, constituye un método de razonar en absoluto infalible pero por lo menos plausible.

Vistas a la luz de la lógica de Peirce, su semiótica, que es todo menos especulativa pero en la cual se incluye explícitamente el pensamiento abductivo, las tentativas de los estudios gramático-textuales, lingüístico-textuales satisfacen la exigencia formal de Chomsky, pero al mismo tiempo han sido efectuadas partiendo de falsas premisas. Hay que reconocer que la línea formal de investigación linguiística ha producido nuevos e inteligentes modelos de análisis y de pensamiento; pero mientras ofrecía una válida alternativa a su (en gran medida impresionista) predecesor, la estilística literaria, como respuesta definitiva estaba destinada a fracasar.

Hasta aquí, he seguido el desarrollo de ciertos aspectos de la lingüística moderna, de la segunda parte de este siglo. Para Chomsky, la lingüística era en esencia teoría de la sintaxis. Como se ha visto, primero se añadió la semántica y más tarde la pragmática. Así, la teoría lingüís- 
tica se aproxima a la teoría semiótica general, según la división que Charles Morris hace del campo de la semiótica en tres ramas: sintaxis, semántica, pragmática (Morris, 1938 y obras posteriores). Según Morris (que a su vez se basaba libremente en Peirce), los signos tienen tres clases de relaciones: la «dimensión sintáctica» o relación de un signo con otro o de varios signos entre sí; la «dimensión semántica» o relación del signo con su objeto u objetos; y la «dimensión pragmática» o la relación entre el signo y sus intérpretes o, más generalmente, sus usuarios. Junto con la teoría de los actos linguísticos, la visión tripartita de Morris constituyó en una teoría (pragma) lingüística del texto como herramienta metodológica o modelo de pensamiento, operando así la perspectiva de un usuario del signo, separado del signo pero no independiente de él. Éste fue uno de los caminos por los que la teoría del texto se desarrolló en una teoría del signo. El otro camino fue el estructuralismo.

La producción e interpretación de textos linguiísticos, entre la multitud de actividades humanas, son formas de comunicación a través de signos. $\mathrm{Si}$ bien esto permite estudiar el fenómeno texto desde la perspectiva de una teoría de signos, la «textología semiótica» (Petöfi, 1986) " es una iniciativa relativamente reciente dentro de la semiótica aplicada. Una importante razón de ello es que la semiótica de textos tal como ha sido practicada hasta ahora se haya concentrado asaz parcialmente en la semiótica linguiística, o teoría de signos de corte saussuriano (incluyendo, hasta cierto punto, el concepto de texto de Lotman); mientras que por su parte el proyecto semiótico de textología basado en la semiótica de Peirce ha recibido escasa atención. En la segunda parte de este artículo, que será publicado en el próximo número de la revista Signa, expondré detalladamente la relevancia de la amplia noción, semiósica, del signo de Peirce y su visión del signo textual para elaborar una teoría textual, o textología basada en el ideario peirciano.

\section{Referencias bibliográficas}

Allén, S. (ed.) (1982). Text Processing: Text Analysis and Generation, Text Typology and Atribution (=proceedings of Nobel Symposium 51). Estocolmo: Almqvist \& Wiksell.

11 El término «textología» fue una invención original de Bajtín. Véase su artículo «Das problems des Textes» (1990: 437-438 nota 2 [nota de los traductores del texto bajtiniano]). 
Bajtín, M. M. (1990). «Das Problem des Textes in der Linguistik, Philologie und in anderen Humanwissenschaften, Versuch einer philosophischen Analyse». Traducción y comentarios de J.R. Döring-Smirnov, A.A. Hansen-Löve, W. Koschmal y H. Schmid. Poetica 22-3/4, 436-487.

BertinetTo, P. M. (1979). «Can We Give a Unique Definition of the Concept "Text"? Reflexions on the Status of Text linguistics». En Text vs Sentence: Basic Questions of Text Linguistics (=Papers in Text linguistics 20-1), J.S. Petöfi (ed.), 143-159. Hamburgo: Helmut Buske.

BREND, R. M. (1986). «Etic/emic». En Encyclopedic Dictionary of Semiotics (=Approache to Semiotics 73), Th. A. Sebeok (ed. gen.), 1, 245-246. Berlín: Mouton de Gruyter.

BRINKER, K. (1979). «Die Gegenstandsbest immung und Aufgabenstel lung der Text linguistik». En Text vs Sentece: Basic Questions of Text Linguistics (=Papers in Text linguistics 20-1), J.S. Petöfi (ed.), 3-12. Hamburgo: Helmut Buske.

Chомsкy, N. (1957): Syntactic Structures (=Janua Linguarum, Series minor 4). La Haya: Mouton.

De Beaugrande, R. A. y Dressler, W. U. (1981). Einfuihrung in die Text linguistik (=Konzepte der Sprach- und Literaturwissenschaft 28). Tübingen: Niemeyer.

FIllmore, Ch. J. (1968). «The Case For Case». En Universals in Linguistic Theory, E. Bach y R. Hams (eds.), 1-88. Nueva York: Holt.

GorlÉE, D. L. (1992). «Symbolic Argument and Beyond: A Peircean View on Structuralist Reasoning». Poetics Today 13-3, 407-423.

GreIMAS, A. J. y CourTès, J. (1979). Sémiotique. Dictionnaire raisonné de la théorie du langage (=Langue, Linguistique, Communication). París: Hachette.

Halliday, M.A.K. y Hasan, R. (1976): Cohesion in English (=English Language Series 9). Londres: Longman.

HARRIS, Z. S. (1952). «Discourse Analysis». Language 28, 1-2. - (1954) «Distributional Structure». Word 10, 146-162.

HJELMSLEV, L. (1943). Omkring sprogteor iens grund 1 æggelse. 4." ed. Copenhague: Akademisk Forlag.

LARSEN, S. E. (1994): «Semiotics». En The Encyclopedia of Language \& Linguistics (10 vols.), R.E. Asher (ed.), vol. 7, 3821-3832. Oxford, Nueva York, etc.: Pergamon Press.

LIEB, H. H. (1981): «A Text: What is it?, A Neglected Question in Text Linguistics». En Text vs Sentence Continued (=Papers in Text linguistics 29), J.S. Petöfi (ed.), 134-158. Hamburgo: Helmut Buske.

MERRELl, F. (1982). Semiotic Foundations: Steps Toward an Epistemology of Written Texts (=Advances in Semiotics). Bloomington, IN: Indiana University Press.

Montague, R. y Schnelle, H. (1972). Universale Grammatik. Braunschweig: Vieweg.

MORRIS, Ch. W. (1938). «Foundations of the Theory of Signs». En Foundations of the Unity of Science, vol. 1, $\mathrm{n}{ }^{\circ} 2,1-14$. Chicago, $\mathrm{L}$ : University of Chicago Press. 
PETöFI, J.S. (1986a). «Report: European Research in Semiotic Textology: A Historical, Thematic, and Bibliographic Guide». Folia Linguistica 20-3/4, 545-571.

- (186b). «Text, Discourse». En Encyclopedic Dictionary of Semitocis (=Approaches to Semitocis 73), Th. A. Sebeok (ed.), 1080-1087. Berlín: Mouton de Gruyter.

PIKE, K.L. ([1954]1967). Language in Relation to a Unified Theory of the Structure of Human Behavior. ${ }^{2}{ }^{a}$ ed. revisada. La Haya: Mouton.

SAPORTA, S. y SEBeOK, S. ([1959]1972): «Linguistics and Content Analysis». En Strukturelle Textanalyse - Analyse du récit - Discourse Analysis (=Studia Semiotica, Collecta Semiotica 1), W. Koch (ed.), 41-60. Hildesheim y Nueva York: Georg Olms.

SAUSSURE, F. DE ([1916]1949). Cours de linguistique générale, Ch. Bally, A. Sechechaye y A. Reidlinger (eds.). 4. a ed. París: Payot.

SINGER, M. (1984). Man's Glassy Essence: Explorations in Semiotic Anthropology (=Advances in Semiotics). Bloomington, IN: Indiana University Press.

VAN DuJ, T. A. (1972). Some Aspects of Text Grammars. La Haya: Mouton. - (1980). Macrostructures: An Interdisciplinary Study of Global Structures in Discourse, Interaction, and Cognition. Hi I Isdale, NJ: Lawrence Er Ibaum Associates.

VirTanen, T. (1990). «On the Definitions of Text and Discourse». Folia Linguistica 24-3/4, 447-455.

Vitacolonna, L. (1988). "“Text"/"Discourse" Definitions". En Text and Discourse Constitution: Empirical Aspects, Theoretical Approaches (=Research in Text Theory 4), J.A. Petöfi (ed.), 421-439. Berlín y Nueva York: Walter de Gruyter.

WeinRICH, H. (1981). «Text as Primun Datum of Linguistics». En Text vs Sentece Continued (=Papers in Text linguistics 29), J.S. Petöfi (ed.), 228230. Hamburgo: Helmut Buske. 